\title{
The Impact of Re-Operation, Relatives and Race on the Oculocardiac Reflex During Strabismus Surgery
}

\author{
Robert W Arnold (1D' \\ Ainsley R Rinner ${ }^{2}$ \\ Andrew W Arnold (iD ${ }^{3}$ \\ Brion J Beerle ${ }^{4}$
}

'The Alaska Blind Child Discovery, Alaska Children's EYE \& Strabismus, Anchorage, AK, USA; ${ }^{2}$ Grace Christian School, Anchorage, AK, USA; ${ }^{3}$ Pacific Northwest University College of Osteopathic Medicine, Yakima, WA, USA; ${ }^{4}$ Chugach Anesthesia Group, Anchorage, AK, USA

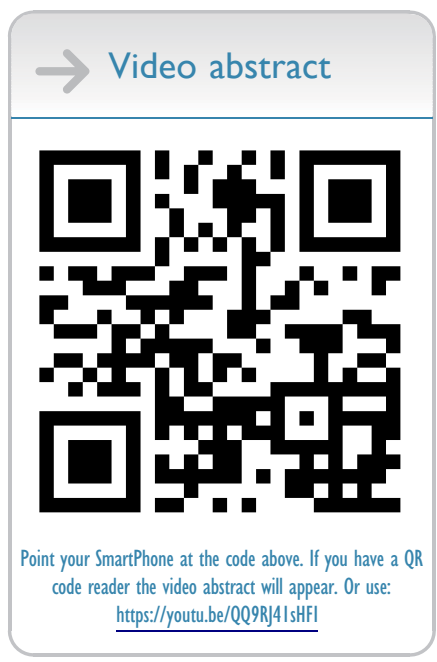

Correspondence: Robert W Arnold Alaska Children's EYE \& Strabismus, 3500 Latouche \#280, Anchorage, AK 99508, USA

Tel + | $907561-1917$

$\mathrm{Fax}+1907563-5373$

Email eyedoc@alaska.net
This article was published in the following Dove Press journal: Clinical Ophthalmology

Purpose: The oculocardiac reflex (OCR) is a trigeminovagal bradycardia elicited by tension on an extraocular muscle (EOM). Using three decades of observational data, we investigated whether or not individual strabismus patients are prone to oculocardiac reflex.

Patients and Methods: All patients undergoing strabismus surgery from 1992 to 2019 had deliberate 10-second, 200-gram square-wave tension on extraocular rectus muscles with anesthetic variables recorded. OCR was defined as the maximally tension-altered heart rate as a percent of stable baseline heart rate.

Results: OCR was compared in 2532 original cases with 323 re-operations. The 169 cases that used anticholinergics (99\% OCR) were excluded from the analysis. The median OCR, a $15 \%$ drop, was found to be $85 \%$ (95\% CI 39\%, 102\%, range 5-151\%). Factors that showed a significant effect on the OCR were the type of EOM with lateral rectus least (KruskalWallis $\left.X^{2}(3)=8, p<0.05\right)$, and adults had less OCR compared to the children $\left(X^{2}(2)=105\right.$, $\mathrm{p}<0.01)$. Factors that showed an augmenting effect on the OCR were peri-operative opioids $\left(X^{2}(6)=62, p<0.01\right)$ and Caucasian race $\left(X^{2}(4)=12, p<0.02\right)$. Gender and iris color were not found to have an impact on OCR. Re-operations and first-degree relatives did not differ from age-matched controls, but EOM- and opioid-adjusted re-operations correlated with their initial cases $(r=0.37)$.

Conclusion: We confirmed the previously published blocking effect of atropine, augmenting impact of opioids, and an inverse relationship of age on OCR. There was a weak proclivity for individuals to be prone to OCR. We found an impact of race with Caucasians having more OCR.

Keywords: trigemino-vagal reflex, re-operation, race, opioid, strabismus surgery, bradycardia

\section{Plain Language Summary}

Over 28 years, general anesthetic variables in adult and pediatric community out-patient general anesthetic strabismus surgical cases were prospectively observed. A large sample size is required to compare the highly variable oculocardiac reflex (OCR). OCR was elicited by uniform 10-second, 200 gram extraocular muscle tension and defined as the maximal tension-altered heart rate as a percent of stable pre-tension heart rate. The 2532 original cases without anticholinergic were compared to 323 reoperations. The frequency distribution of OCR was not normally distributed with median $86 \%$ and interquartile range $67 \%$ to $97 \%$. There was no impact based on gender or iris color, but adults had less percent change bradycardia than children. If opioids were used, remifentanyl and hydromorphone produced the most OCR augmentation. Of rectus muscles, the lateral rectus was associated with the 
least OCR bradycardia. A weak individual proclivity to OCR was shown; in reoperation cases the second OCR was correlated to the original. The OCR in first degree relatives did not differ. Caucasians had more bradycardia than other races or ethnicities.

\section{Introduction}

The oculocardiac reflex ${ }^{1}$ (OCR), also known as one of the trigeminovagal reflexes, ${ }^{2}$ usually results in vagal bradydysrhythmia elicited by orbital stimulus and classically by extraocular muscle tension.

Three persons can influence an oculocardiac reflex during strabismus surgery: the anesthesiologist, the ophthalmic surgeon and the patient.

The anesthesiologist has great influence on the oculocardiac reflex. ${ }^{3}$ Bradycardia can be reduced by adequate doses of anticholinergic medication, ${ }^{4}$ whereas bradycardia may be augmented by fast-acting opioids ${ }^{5-7}$ as well as dexmedetomidine. ${ }^{8}$ The ocular surgeon also has great influence on OCR. ${ }^{9}$ Abrupt, high levels of tension ${ }^{6}$ over several seconds elicit the most bradycardia while brief, gentle tension, with gradual onset, ${ }^{10}$ and release - usually at the request of the anesthesiologist - will usually curb the bradycardia. Retrobulbar ${ }^{11,12}$ or sub-Tenons ${ }^{13}$ block, after it has taken full effect, will also reduce or eliminate OCR.

The degree of oculocardiac reflex varies greatly from one case to the next, ${ }^{14}$ even with similar anesthetic protocols. Due to the wide variation in OCR between cases and patients, a large sample size is required to detect small differences in effect.

It has not been known whether or not an individual might have a predictable proclivity of the oculocardiac reflex. A similar degree of OCR has been observed in identical twins. ${ }^{15}$ Patients who demonstrated profound intra-operative oculocardiac reflex during strabismus surgery were not particularly prone to bradycardia during other vagal maneuvers ${ }^{16}$ which have been shown to produce greater average heart rate changes than surgical OCR. ${ }^{14}$ Moonie was unable to predict intraoperative OCR using pre-operative globe pressure. ${ }^{17}$ Pre-tension heart rate variability may predict more profound OCR. ${ }^{18}$ An attempt was made to use neural networks to predict OCR in a very small number of strabismus patients. ${ }^{19}$ Brown eyes were once thought to have more OCR than blue eyes. $^{20}$ The extraocular muscle type has influenced OCR with several larger studies finding that the medial rectus produces more than the lateral rectus muscle. ${ }^{21,22}$
Intraoperative OCR may help predict vasovagal activity during subsequent suture adjustment. ${ }^{23}$ Apt did not find repeat OCR on five patients with re-operations, ${ }^{24}$ but prosthesis manipulation produced OCR in the same patient 2 years apart. $^{25}$

We observed uniformly elicited oculocardiac reflex with a large sample size gathered over three decades to determine if there is any individual proclivity or predictability.

\section{Methods}

From 1992 to 2019, in a cross-sectional trial, consecutive cases of strabismus surgery by one surgeon (RWA) were prospectively documented under an observational protocol approved by the Institutional Review Board of Providence Hospital (Clinical Trial NCT04353960). Written consent was not required. The study complies with the Health Information Portability and Accountability Act and the Declaration of Helsinki. De-identified data are available from http://www.abcd-vision.org/OCR/Ak\%20OCR\% 20data\%204-2020.pdf.

The oculocardiac reflex was elicited by a tension gauge quantified, square-wave tension, applied uniformly at 200 gram of pressure for 10 seconds on gently isolated extraocular rectus muscles. Before any surgery on the globe or extraocular muscles, the anesthesiologist assured stable blood pressure and oxygen saturation. A sterile tension gauge was inserted into holes drilled in Jameson muscle hooks after gentle conjunctival incision, Tenon's capsule dissection and then a gentle sweep of the thin Jameson tip under extraocular rectus muscle tendon. If the conjunctival incision was between the inferior rectus and a horizontal rectus, the presence or absence of the inferior rectus was confirmed by exploration with the Jameson hook. From electrocardiograph monitor, stable pre-tension heart rate, and then maximal tension-altered heart rate (either bradycardia or tachycardia) were recorded. An example of profound oculocardiac reflex can be observed: https://youtu. be/HtyMI7pqTvE. The oculocardiac reflex is reported as a percent of pre-tension levels so bradycardia is from $99 \%$ to as low as $5 \%$, whereas a tachycardic response is greater than $100 \%$. For example, from a stable baseline heart rate of 120 beat per minute (bpm) in a child, extraocular rectus muscle 10-second, 200-gram tension dropped heart rate $33 \%$ to $80 \mathrm{bpm}$, we would report OCR of $67 \%$. On the other hand, from a stable baseline heart rate of $60 \mathrm{bpm}$ in an adult, identical 200 gram, 10-second tension on an extraocular rectus muscle increasing heart rate $33 \%$ to 80 
bpm, we would report OCR of 133\%. Additional anesthetic variables including inhalational agents and end-tidal concentration, carbon dioxide levels, injected sedatives, anticholinergic medications, muscle relaxants, and preoperative sedatives were recorded. Also recorded were birthdate, gender, race, weight, associated neurologic disease or syndrome, whether the case was a re-operation, and if a first-degree relative had also been included in this oculocardiac reflex study.

Recognizing that anticholinergics, ${ }^{4}$ opioids ${ }^{5}$ and extraocular muscle types ${ }^{6,26}$ influence OCR, and to reduce bias in our comparisons, cases with anticholinergic medication before extraocular tension were quantified for comparison, but excluded from the analysis. Cases with orbital block or pacemaker were also excluded. To further increase uniformity in comparisons between cases, a factor related to the mean OCR was applied to address the impact of opioids or choice of EOM tensioned. Re-operation cases and cases with first-degree relatives were analyzed to determine the absolute difference and standard deviation between adjusted oculocardiac reflex measurements.

A control group was generated using other agematched, original, adjacent cases that did not have anticholinergic medication from our database. The difference between adjacent cases and the standard deviation was calculated and averaged for both control group and our comparison groups (re-operations, relatives and race). If there is a genetically inherited proclivity to OCR, the mean difference in the control group should be less than that of the control group.

\section{Statistical Methods}

Whether or not frequency distributions are normally distributed are analyzed by skewness and kurtosis. Data not normally distributed are presented with medians, interquartile ranges and $95 \%$ confidence intervals. Comparison of distributions that are not normally distributed applies the Mann-Whitney (two groups) and Kruskal-Wallis (more than two groups) tests with $\mathrm{p}>0.05$ considered significant. A linear regression with Pearson coefficient was used to compare first to second EOM within non-anticholinergic cases with two or more EOM tensioned.

\section{Sample Size}

To detect a difference of $3 \%$ between two groups with mean $80 \%$ and standard deviation $20 \%$ with type- 1 error rate alpha 0.05 and power (1-beta) 0.8 , a sample size in each group of about 700 is needed. A sample size of 349 is needed to tell $3 \%$ difference between a known population. To detect a confidence interval of $5 \%$ with $95 \%$ confidence level, given the standard deviation of $20 \%$, a sample size of 246 is needed. For proportions with standard deviation $20 \%$, sampling ratio 1.0 , power 0.8 and type 1 error rate alpha 0.05 , to detect a $5 \%$ difference takes a sample size of 901. To determine whether a correlation $r$ differs from zero, with alpha $=0.05$ and beta $=0.20$, an $\mathrm{r}$ of 0.1 would require a sample size of 783. Prolonged uniform data collection and the use of continuous variables rather than ordinal (other authors define OCR as $>20 \%$ heart rate drop) to increase statistical power improves the validity of conclusions regarding the widely variable OCR.

\section{Results}

From 1992 to 2019, oculocardiac reflex with uniform 200gram, 10-second tension was prospectively measured in 3122 cases and in 2676 patients, with mean \pm SD age 15.6 \pm 19 years (range 0.1-90 years). Excluded were 5 with orbital block, 1 with pacemaker and 169 cases with bradycardia reduced from $81 \pm 22 \%$ to just $95.1 \pm 12 \%$ as a result of anticholinergic administered at the choice of the anesthesiologist (Mann-Whitney $z=11.0, \mathrm{P}<0.01$ ). Details of this and several other influential variables highlighting median, quartiles, 95th percentiles and ranges are given in Table 1.

In 2532 original cases with no anticholinergic, deliberate, pre-determined tension on extraocular rectus muscles produced a change from a pre-heart rate of $101 \pm 30 \mathrm{bpm}$ down to $81 \pm 32 \mathrm{bpm}$ (Table 1). The frequency distribution of oculocardiac reflex was not normally distributed with kurtosis 0.94 and skewness -1.07 (Figure 1) so non-parametric values are reported. Some authors define OCR as a proportion with more than a given percent heart rate reduction; a ten percent drop in heart rate was demonstrated by $57.0 \%$ of our cases, a twenty percent drop in heart rate to OCR $80 \%$ or less was shown by $40.6 \%$, and profound OCR with bradycardia to $50 \%$ or less was attained by $9.4 \%$ of the cases (Table 1 ).

No significant difference in oculocardiac reflex was noted due to gender (Mann-Whitney $z=0.19, \mathrm{P}=0.85$ ) or due to iris color (Kruskal-Wallis $\mathrm{X}^{2}(3)=4.5, \mathrm{p}=0.21$; Table 1 and Figure 2).

We compared the median OCR of 1172 preschoolers less than age 6 (OCR of 84\%), 731 school age (6-19 years; OCR of $85 \%$ ), and 629 adults older than 20 (OCR of $95 \%$ ) finding less bradycardia in the adult patient 
Table I Non-Parametric Statistics for Individual and Intraoperative Characteristics Impacting the Oculocardiac Reflex (OCR)

\begin{tabular}{|c|c|c|c|c|c|c|c|c|c|c|c|c|c|c|}
\hline & \%OCR & & Count & Min & $5 \%$ & QI & Median & Q3 & $95 \%$ & Max & Mean & SD & $\begin{array}{l}>20 \\
\text { Drop }\end{array}$ & $\begin{array}{l}>50 \\
\text { Drop }\end{array}$ \\
\hline EOM & & $\begin{array}{l}\text { Lateral rectus } \\
\text { Medial rectus } \\
\text { Inferior rectus } \\
\text { Superior rectus }\end{array}$ & $\begin{array}{l}212 \\
374 \\
1784 \\
162\end{array}$ & $\begin{array}{l}8 \\
6 \\
\frac{5}{6}\end{array}$ & $\begin{array}{l}41 \\
43 \\
37 \\
45\end{array}$ & $\begin{array}{l}71 \\
68 \\
67 \\
66\end{array}$ & $\begin{array}{l}89 \\
87 \\
85 \\
84\end{array}$ & $\begin{array}{l}99 \\
98 \\
97 \\
95\end{array}$ & $\begin{array}{l}103 \\
102 \\
102 \\
101\end{array}$ & $\begin{array}{l}129 \\
117 \\
151 \\
115\end{array}$ & $\begin{array}{l}83 \\
81 \\
79 \\
79\end{array}$ & $\begin{array}{l}21 \\
21 \\
22 \\
20\end{array}$ & $\begin{array}{l}33 \\
40 \\
42 \\
43\end{array}$ & $\begin{array}{l}7 \\
11 \\
11 \\
7\end{array}$ \\
\hline Race & & $\begin{array}{l}\text { Asian-Pacific } \\
\text { Black } \\
\text { Alaska Native } \\
\text { Hispanic } \\
\text { Caucasian }\end{array}$ & $\begin{array}{l}30 \\
44 \\
59 \\
31 \\
454\end{array}$ & $\begin{array}{l}30 \\
26 \\
8 \\
15 \\
8\end{array}$ & $\begin{array}{l}54 \\
36 \\
31 \\
52 \\
41\end{array}$ & $\begin{array}{l}84 \\
74 \\
71 \\
75 \\
65\end{array}$ & $\begin{array}{l}95 \\
93 \\
90 \\
88 \\
81\end{array}$ & $\begin{array}{l}99 \\
99 \\
98 \\
100 \\
97\end{array}$ & $\begin{array}{l}104 \\
101 \\
101 \\
102 \\
101\end{array}$ & $\begin{array}{l}104 \\
101 \\
108 \\
103 \\
127\end{array}$ & $\begin{array}{l}87 \\
81 \\
82 \\
85 \\
78\end{array}$ & $\begin{array}{l}17 \\
23 \\
22 \\
19 \\
21\end{array}$ & $\begin{array}{l}21 \\
32 \\
34 \\
35 \\
47\end{array}$ & $\begin{array}{l}3 \\
11 \\
10 \\
3 \\
10\end{array}$ \\
\hline Sex & & $\begin{array}{l}\text { Male } \\
\text { Female }\end{array}$ & $\begin{array}{l}1262 \\
1270\end{array}$ & $\begin{array}{l}6 \\
5\end{array}$ & $\begin{array}{l}40 \\
38\end{array}$ & $\begin{array}{l}67 \\
68\end{array}$ & $\begin{array}{l}86 \\
85\end{array}$ & $\begin{array}{l}97 \\
97\end{array}$ & $\begin{array}{l}102 \\
101\end{array}$ & $\begin{array}{l}|3| \\
15 \mid\end{array}$ & $\begin{array}{l}80 \\
80\end{array}$ & $\begin{array}{l}21 \\
22\end{array}$ & $\begin{array}{l}41 \\
40\end{array}$ & $\begin{array}{l}10 \\
9\end{array}$ \\
\hline Age & & $\begin{array}{l}\text { Preschool } \\
\text { School } \\
\text { Adult }\end{array}$ & $\begin{array}{l}1172 \\
731 \\
629\end{array}$ & $\begin{array}{l}8 \\
5 \\
6\end{array}$ & $\begin{array}{l}44 \\
33 \\
26\end{array}$ & $\begin{array}{l}65 \\
64 \\
78\end{array}$ & $\begin{array}{l}82 \\
83 \\
95\end{array}$ & $\begin{array}{l}95 \\
96 \\
100\end{array}$ & $\begin{array}{l}101 \\
102 \\
105\end{array}$ & $\begin{array}{l}151 \\
129 \\
122\end{array}$ & $\begin{array}{l}78 \\
78 \\
85\end{array}$ & $\begin{array}{l}19 \\
22 \\
23\end{array}$ & $\begin{array}{l}46 \\
45 \\
26\end{array}$ & $\begin{array}{l}8 \\
10 \\
11\end{array}$ \\
\hline $\begin{array}{l}\text { Iris } \\
\text { color }\end{array}$ & & $\begin{array}{l}\text { Blue } \\
\text { Brown } \\
\text { Green } \\
\text { Hazel }\end{array}$ & $\begin{array}{l}667 \\
732 \\
46 \\
50\end{array}$ & $\begin{array}{l}6 \\
5 \\
16 \\
14\end{array}$ & $\begin{array}{l}43 \\
43 \\
42 \\
26\end{array}$ & $\begin{array}{l}67 \\
72 \\
73 \\
60\end{array}$ & $\begin{array}{l}85 \\
87 \\
86 \\
85\end{array}$ & $\begin{array}{l}97 \\
98 \\
95 \\
97\end{array}$ & $\begin{array}{l}103 \\
102 \\
100 \\
102\end{array}$ & $\begin{array}{l}151 \\
125 \\
105 \\
129\end{array}$ & $\begin{array}{l}80 \\
82 \\
81 \\
78\end{array}$ & $\begin{array}{l}21 \\
20 \\
19 \\
25\end{array}$ & $\begin{array}{l}41 \\
37 \\
38 \\
40\end{array}$ & $\begin{array}{l}9 \\
7 \\
9 \\
13\end{array}$ \\
\hline Opioid & & $\begin{array}{l}\text { No opioid } \\
\text { Morphine } \\
\text { Sufentanyl } \\
\text { Fentanyl } \\
\text { Remifentanil } \\
\text { Hydromorphone } \\
\text { Non-anticholinergic } \\
\text { Anticholinergic }\end{array}$ & $\begin{array}{l}1496 \\
44 \\
19 \\
847 \\
53 \\
73 \\
2532 \\
138\end{array}$ & $\begin{array}{l}5 \\
15 \\
14 \\
6 \\
13 \\
20 \\
5 \\
40\end{array}$ & $\begin{array}{l}46 \\
48 \\
14 \\
29 \\
18 \\
37 \\
39 \\
71\end{array}$ & $\begin{array}{l}72 \\
65 \\
56 \\
63 \\
48 \\
61 \\
67 \\
95\end{array}$ & $\begin{array}{l}88 \\
86 \\
84 \\
81 \\
78 \\
76 \\
86 \\
99\end{array}$ & $\begin{array}{l}98 \\
96 \\
96 \\
96 \\
92 \\
93 \\
97 \\
100\end{array}$ & $\begin{array}{l}102 \\
107 \\
103 \\
102 \\
105 \\
100 \\
102 \\
103\end{array}$ & $\begin{array}{l}151 \\
110 \\
103 \\
122 \\
122 \\
121 \\
151 \\
112\end{array}$ & $\begin{array}{l}83 \\
80 \\
74 \\
76 \\
70 \\
75 \\
80 \\
95\end{array}$ & $\begin{array}{l}20 \\
22 \\
28 \\
23 \\
28 \\
22 \\
21 \\
12\end{array}$ & $\begin{array}{l}35 \\
36 \\
42 \\
48 \\
52 \\
56 \\
41 \\
6\end{array}$ & $\begin{array}{l}6 \\
9 \\
16 \\
13 \\
26 \\
15 \\
10 \\
0\end{array}$ \\
\hline Re-op & & $\begin{array}{l}\text { OCR I } \\
\text { OCR re-operation } \\
\text { OCR adjusted I } \\
\text { OCR adjusted re-OP }\end{array}$ & $\begin{array}{l}323 \\
323 \\
323 \\
323\end{array}$ & $\begin{array}{l}13 \\
8 \\
18 \\
10\end{array}$ & $\begin{array}{l}46 \\
33 \\
53 \\
51\end{array}$ & $\begin{array}{l}68 \\
68 \\
75 \\
77\end{array}$ & $\begin{array}{l}85 \\
88 \\
88 \\
91\end{array}$ & $\begin{array}{l}97 \\
98 \\
96 \\
98\end{array}$ & $\begin{array}{l}102 \\
104 \\
101 \\
102\end{array}$ & $\begin{array}{l}120 \\
159 \\
120 \\
129\end{array}$ & $\begin{array}{l}81 \\
81 \\
84 \\
85\end{array}$ & $\begin{array}{l}20 \\
23 \\
16 \\
18\end{array}$ & $\begin{array}{l}41 \\
39 \\
34 \\
29\end{array}$ & $\begin{array}{l}7 \\
9 \\
3 \\
5\end{array}$ \\
\hline & $\Delta \% \mathrm{HR}$ & $\begin{array}{l}\text { Re-op } \\
\text { Adjacent Age } \\
\text { Relative }\end{array}$ & $\begin{array}{l}323 \\
2454 \\
28\end{array}$ & $\begin{array}{l}0 \\
0 \\
0\end{array}$ & $\begin{array}{l}1 \\
1 \\
0\end{array}$ & $\begin{array}{l}6 \\
5 \\
6\end{array}$ & $\begin{array}{l}12 \\
12 \\
11\end{array}$ & $\begin{array}{l}23 \\
24 \\
23\end{array}$ & $\begin{array}{l}44 \\
44 \\
37\end{array}$ & $\begin{array}{l}60 \\
72 \\
46\end{array}$ & & & & \\
\hline $\mathrm{HR}$ & $\mathrm{bpm}$ & $\begin{array}{l}\text { Pre-HR } \\
\text { OCR HR }\end{array}$ & $\begin{array}{l}2532 \\
2532\end{array}$ & $\begin{array}{l}42 \\
4\end{array}$ & $\begin{array}{l}60 \\
32\end{array}$ & $\begin{array}{l}80 \\
61\end{array}$ & $\begin{array}{l}101 \\
78\end{array}$ & $\begin{array}{l}120 \\
100\end{array}$ & $\begin{array}{l}143 \\
134\end{array}$ & $\begin{array}{l}176 \\
168\end{array}$ & & & & \\
\hline
\end{tabular}

Note: OCR is expressed as the maximal percent change (to OCR HR) from baseline heart rate (pre HR). Except for the category "Cholinergics", all data represent cases without anticholinergic medication. Max and Min are ends of the range of values with $5 \%$ and $95 \%$ represent corresponding percentiles and QI and Q3 encompass the middle two quartiles. Mean and standard deviation (SD) reported and proportion with heart rate drop more than $20 \%$ (>20 drop) and more than $50 \%$ ( $>50$ drop). Re-op represents cases with OCR monitored during initial strabismus surgery case and also during re-operations. The OCR is adjusted by appropriate factors so each case resembles and inferior rectus done with no opioid. $\triangle \% \mathrm{HR}$ is the Absolute difference between initial and re-operative OCR

Abbreviations: OCR, oculocardiac reflex; H.R, heart rate; QI and Q3, interquartile range; bpm, beats per minute; EOM, extraocular muscle; SD, standard deviation; ANOVA, analysis of variance; C.I, confidence interval.

population. Age does have an influence on oculocardiac reflex (Kruskal-Wallis $\mathrm{X}^{2}(2)=85, \mathrm{p}<0.01$, Figure 3).

Extraocular muscle type influences oculocardiac reflex with the lateral rectus producing the least median bradycardia (89\%) and the superior rectus the most $(84 \%$; Figure 2). We have not collected data on oblique muscles since the surgical approach to the obliques involves prior tension on rectus muscles which alters the stable baseline 


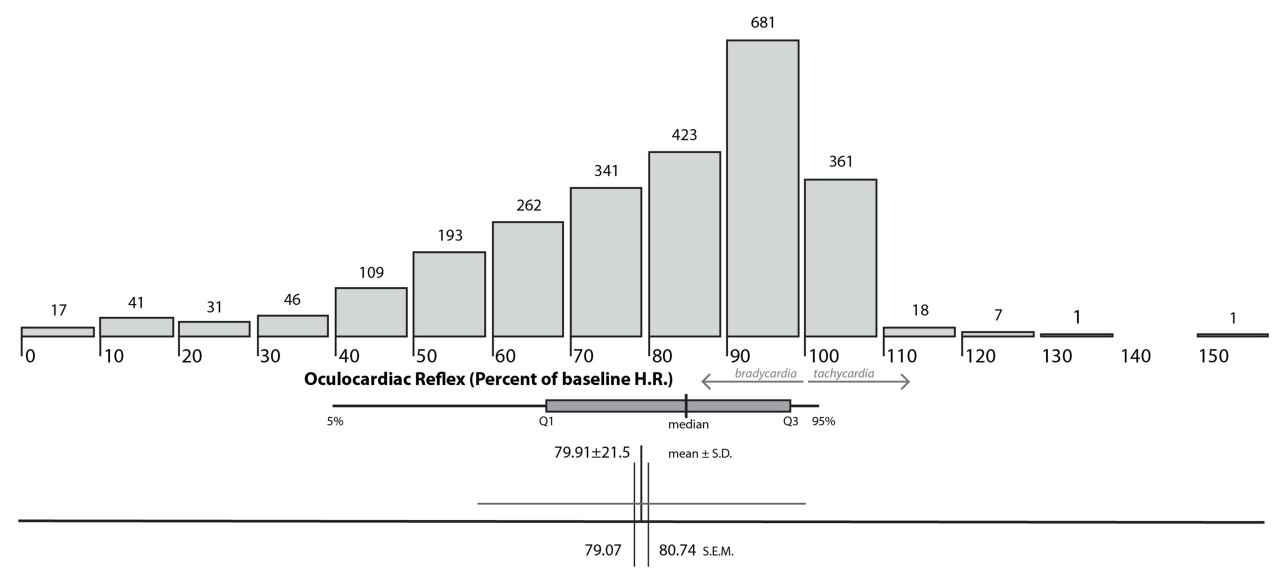

Figure I Frequency distribution of oculocardiac reflex, in 2532 original cases without anticholinergic. OCR was elicited by I0-second, 200 -gram square-wave tension on extraocular rectus muscle.

Abbreviations: HR, heart rate from intraoperative ECG monitor; SD, standard deviation; QI and Q3, first and third quartiles; 5\% and 95\%, corresponding percentiles; SEM, standard error of the mean.

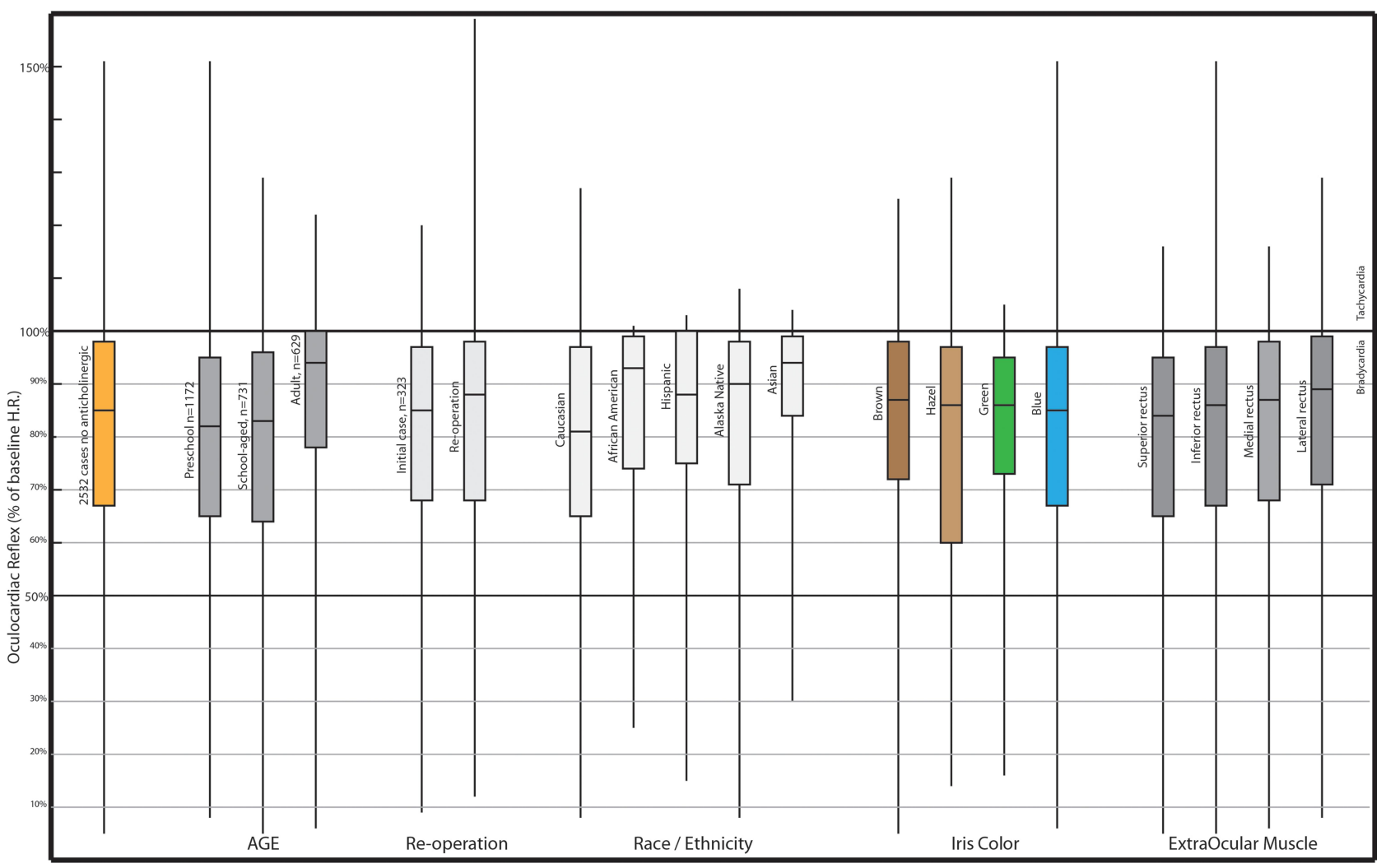

Figure 2 Box and whisker plots of oculocardiac reflex medians as a percent of baseline heart rate. The box surrounds the middle quartiles with whiskers extending to the minimum and maximum. To the left represents all initial cases without anticholinergic medication while the remaining are groupings associated with age groupings, reoperations, race and ethnicity, iris color and which extraocular muscle was involved.

heart rate. For the past two decades, the majority of the cases in this study have been elicited from the inferior rectus which can be approached by an inferior incision adjacent to either the inferior, the lateral or the medial rectus muscle tendons with its median OCR $85 \%$. EOM type was found to influence OCR (Kruskal-Wallis $\mathrm{X}^{2}(3)=7.99, \mathrm{p}<0.05$ ).

Fast-acting opioids as a part of induction or maintenance anesthesia had an influence on oculocardiac reflex (Kruskal- 


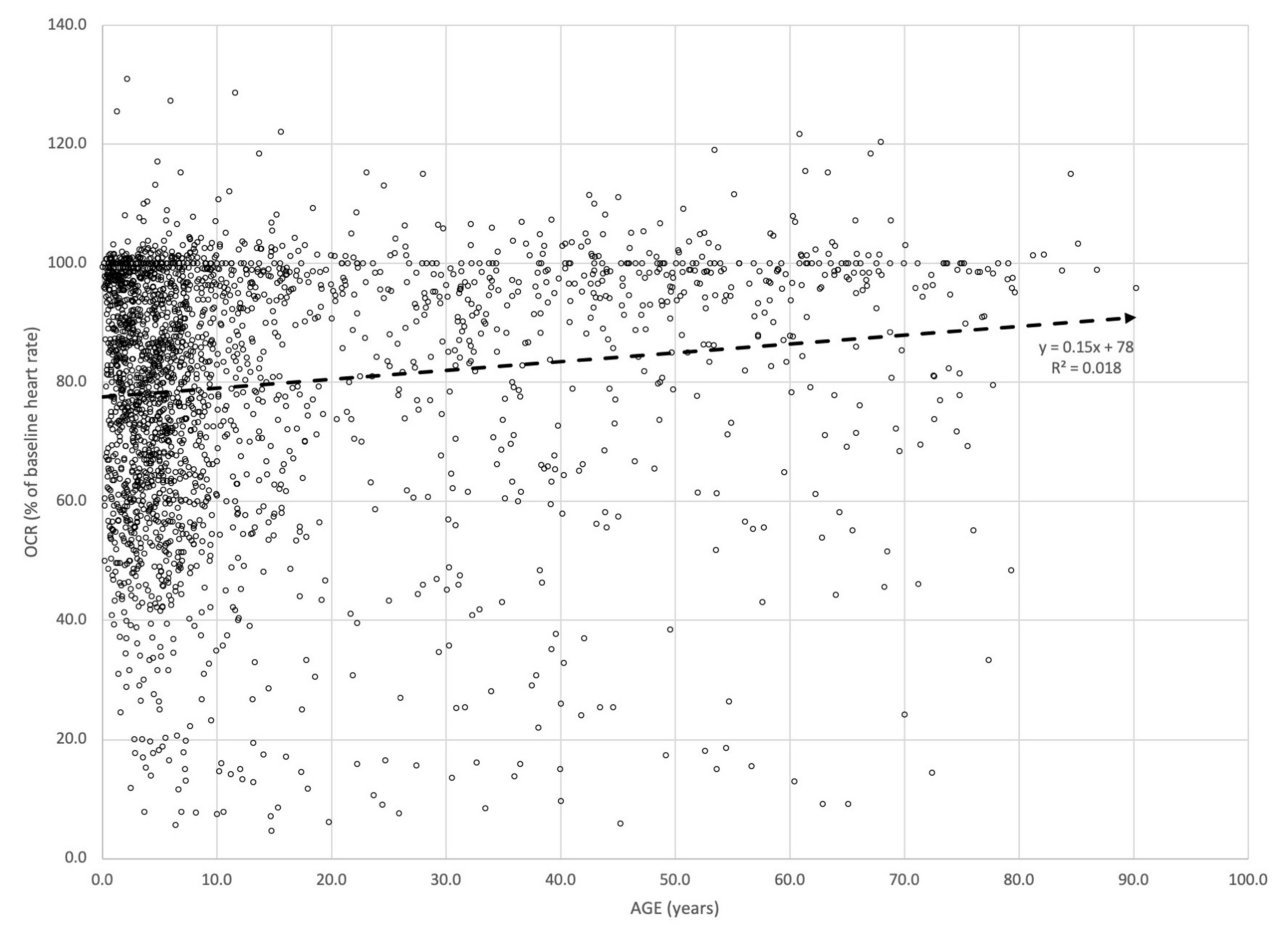

Figure 3 The impact of age on the oculocardiac reflex (OCR). OCR is defined as the percent of baseline heart rate with each of these 2532 cases an original case without anticholinergic medication.

Wallis $X^{2}(6)=57.6, p<0.01$, Figure 2). Remifentanil produced a median OCR of $78 \%$ compared to no opioid at $88 \%$.

With opioids and EOM type having a known impact on OCR, an adjustment factor was applied to have each case approximate an opioid-free case with inferior rectus tension. As such, each lateral rectus case OCR was multiplied by 0.954 , each medial rectus 0.979 and each superior rectus by 1.014 . To approximate no opioid, each hydromorphone case was multiplied by 1.116 , each morphine by 1.037, sufentanyl 1.080, fentanyl 1.094, and each remifentanil by 1.212. Confirming these transformations, our adjusted OCR mean (ANOVA) was not influenced by $\operatorname{EOM}(F(3,2528)=0.87, \mathrm{p}=0.46)$ and also not influenced by presence of opioid $(F(5,2526)=0.45, \mathrm{p}=0.81)$.

The influence of race and ethnicity was significant (Kruskal-Wallis $\mathrm{X}^{2}(4)=12.3, \mathrm{p}=0.02$ ). For cases with race or ethnicity recorded, the median OCR ranged from least bradycardia of $95 \%$ in Asians to the most at $81 \%$ in Caucasians (Figure 2).

There were 446 re-operations. Excluding 31 re-operations with anticholinergics, repeat operations occurred at least once in 323 patients. There was a median interval of 2.6 years (range 0.1 to 20.5 years) between initial and first non-anticholinergic re-operation. There were 109 with two re-operations, 53 with three re-operations, 9 with five re-operations and
6 with seven re-operations. The median original OCR $(85.2 \%$, $95 \%$ CI $46.4 \%, 101.5 \%$ ) and the median of 323 re-operations (88.1\%, 95\% CI 33.3\%, 104.3\%) did not differ (MannWhitney $z=0.87, \mathrm{p}=0.38$ ). When OCR was adjusted for extraocular muscle type and presence of opioid, the original surgery $(87.9 \%, 95 \%$ CI $52.6 \%, 100.8 \%)$ tended to show more bradycardia than the re-operation $(90.6 \%, 95 \%$ CI 51.4\%, 102.4\%, $\mathrm{p}=0.05)$. The median absolute difference between original surgery and the first re-operation $(12.1 \%, 95 \%$ CI $0.8 \%$, $44 \%)$ and the adjacent, age-matched control (12.1\%, 95\% CI $0.7 \%, 43.9 \%$ ) did not differ (Mann-Whitney $z=0.27, \mathrm{p}=0.79$ ).

When oculocardiac reflex was adjusted for type of EOM and influence of opioid, the re-operation (y) was related to the initial case $(\mathrm{x})$ by the linear relationship $\mathrm{y}$ $=0.4 \mathrm{x}+52 \%$ with Pearson coefficient $\mathrm{r}=0.37, \mathrm{t}=7.1$, $\mathrm{p}<0.1$ (Figure 4). The absolute difference in adjusted OCR (d) did not correlate with the time interval ( $t$ years) between original case and re-operation $\mathrm{d}=0.17 \mathrm{t}$ $+13 \%\left(r^{2}=0.003\right)$.

Profound oculocardiac reflex with percent heart rate to less than $50 \%$ pre-tension HR during initial, non-anticholinergic cases was noted in 239 of 2532 (9.4\%) original cases. Showing no significant difference, $24(7 \%)$ of the 323 initial cases with re-operations had profound OCR $(\mathrm{X} 2=1.43, \mathrm{p}=0.23)$ but of those, a higher proportion $(9 \%$ 


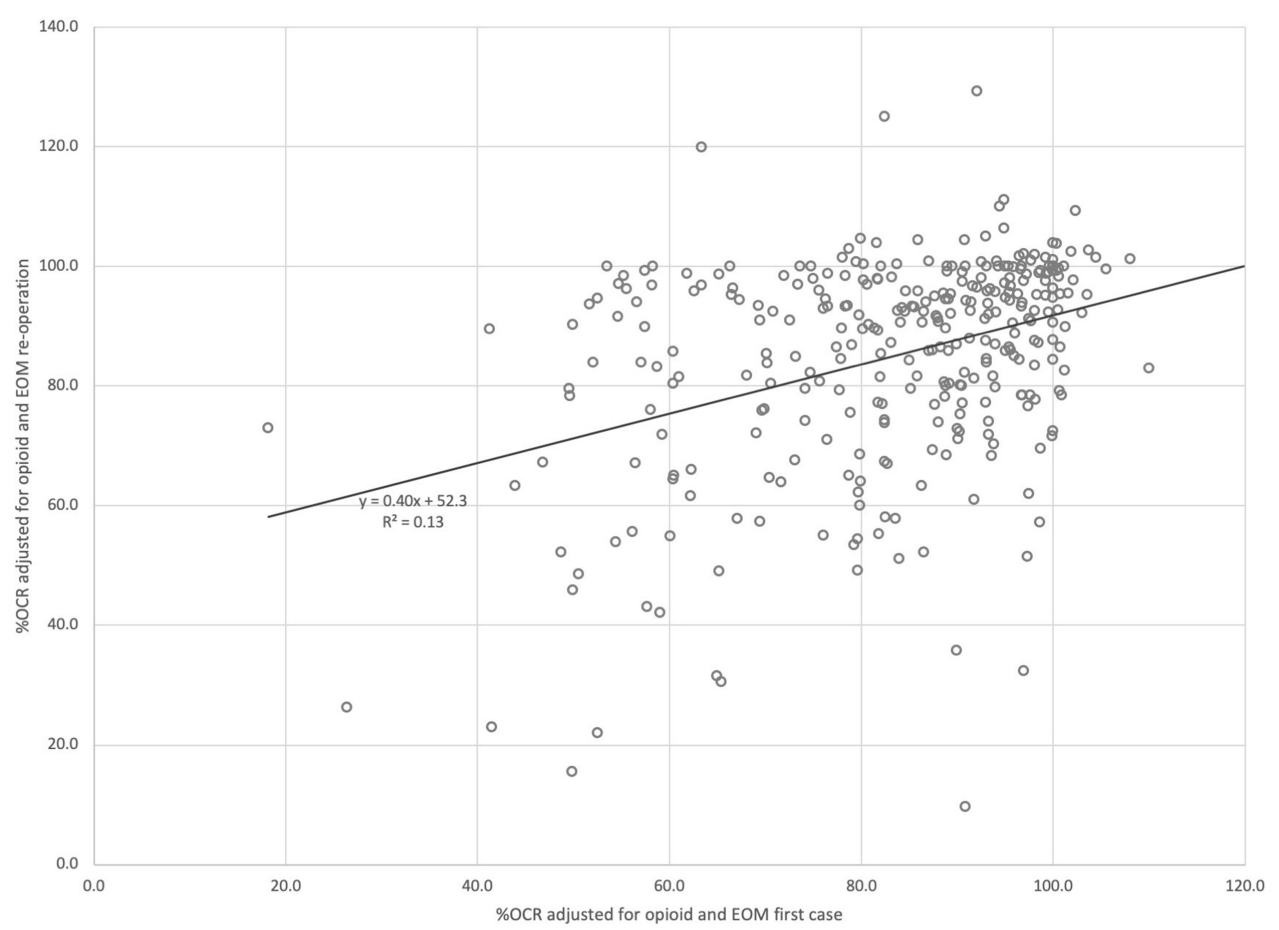

Figure 4 Correlation between 323 initial and re-operation for oculocardiac reflex adjusted for opioids and type of rectus muscle.

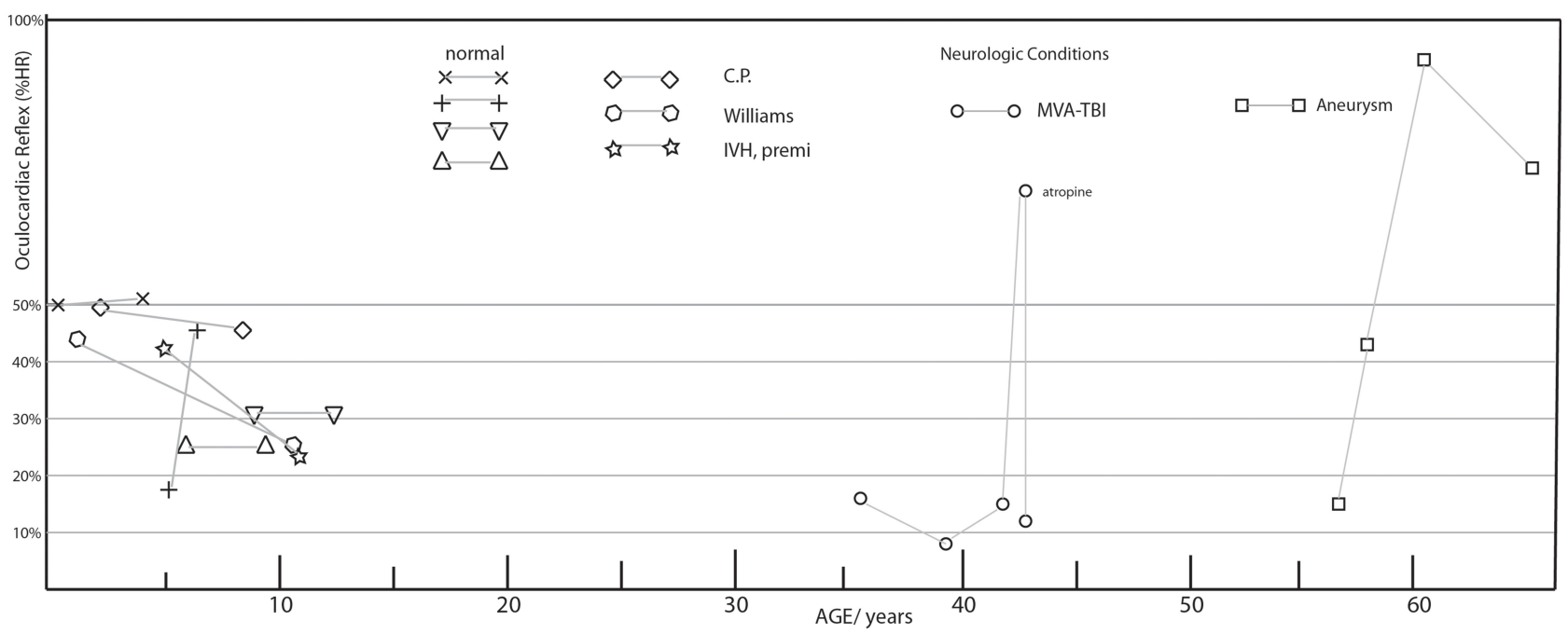

Figure 5 Profound OCR and re-operation. Cases at given ages with an OCR less than $50 \%$ of baseline heart rate who also had profound OCR on re-operation. Five of these nine cases had neurologic impairment.

or $38 \%$ ) had profound OCR again on re-operation $\left(\mathrm{X}^{2}=23.5, \mathrm{p}<0.01 ;\right.$ Figure 5).

\section{Relatives}

The absolute difference in oculocardiac reflex between 28 first-degree relatives who both had strabismus surgery did not differ from a control group of age-matched adjacent patients. (Mann-Whitney $z=0.18, \mathrm{p}=0.86$; Table 1).

\section{Discussion}

This is the largest known, single-center, deliberate study of oculocardiac reflex with its profound individual variability. We did not find a profound inherited proclivity to oculocardiac reflex. Instead, we found a weak, individual proclivity to oculocardiac reflex based on the correlation of over 300 re-operative cases, even though the absolute difference and the standard deviation of re-operations did not differ from 
age-matched controls. A disproportionately large group with initial profound oculocardiac reflex had a repeat profound OCR with one or more re-operations. First-degree relatives were not any more likely to have similar oculocardiac reflex than controls. We found that race influenced oculocardiac reflex with Caucasians having more bradycardia and Alaska Natives, African Americans and Asians having less.

We confirmed that OCR is influenced by extraocular muscle type $\mathrm{e}^{5,26}$; the inferior rectus produces more than the lateral rectus. Fast-acting opioids again ${ }^{5}$ were shown to augment the oculocardiac reflex. We confirmed that older patients have less oculocardiac reflex ${ }^{27}$ even when it is expressed as a percent change in heart rate. We did not find a significant correlation between the absolute difference in re-operative adjusted OCR and the time interval between cases from zero to two decades. Despite the small decrease in OCR with increasing age, our sample of reoperations did not show a corresponding age-related impact of the interval between operations.

As mentioned in the introduction, a large sample size is required to demonstrate significant differences in OCR. Four other authors have published findings on OCR based on sample sizes greater than 200. One of the larger OCR studies was done by Pöntinen with 810 strabismus and other eye cases utilizing "deliberate" extraocular muscle pull though the actual EOM tension and duration were not reported. ${ }^{28}$ Fry studied 363 medial rectus surgeries attempting to prove his hypothesis that brown eyes displayed greater OCR. ${ }^{20}$ We also investigated the impact of iris color, but used controlled tension on EOM, and found OCR is not influenced by iris color. ${ }^{26}$ Apt found more medial rectus OCR than lateral rectus during strabismus surgery in 243 patients and 623 muscles with EOM tension "as much as was safe". ${ }^{29}$ In 2000 with $247^{30}$ patients and again in 2001 with 301 patients, ${ }^{31}$ Welters focused on postoperative nausea and vomiting (reduced with rectal dimenhydrinate) while also observing similar rates of OCR during strabismus surgery.

\section{Strengths and Weaknesses}

A major strength of this study is that extraocular muscle stimulus for the reflex - the amount, wave-form and duration of tension - has been deliberately controlled and repeated in each case over three decades. We strive for uniformity by expressing OCR as a percent change in heart rate, preferentially utilizing the inferior rectus, adjusting for type of EOM (if not inferior rectus), and adjusting for the presence of opioid. The mean effect of the combined adjustment was found to reduce the significance of those important variables. Weaknesses of this study include that not every variable has been monitored since the beginning of the data collection. Also, this is not a study of a strictly defined anesthetic protocol; not all doses and delivery of medications have been uniform, rather this represents a collection of experiences and preferences of multiple anesthesiologists in a community, outpatient setting.

With careful monitoring of cardiovascular and respiratory function before and during strabismus surgery, no persistent adverse sequelae were observed; no patient required admission to intensive care following strabismus surgery.

\section{Conclusion}

There exists some limited inherited propensity for oculocardiac reflex. OCR occurs least in adults, least with the lateral rectus muscle, and more in Caucasians.

\section{Data Sharing Statement}

Data Access: http://www.abcd-vision.org/OCR/Ak\% 200CR\%20data\%204-2020.pdf.

\section{Acknowledgment}

Clinical Trials Registry: NCT04353960.

\section{Funding}

There is no funding to report.

\section{Disclosure}

Financial Disclosure: Robert W Arnold is the president of Glacier Medical Software that developed ROP-Check cloud-based software and also PDI Check that makes a vision screening game for the Nintendo 3DS. He coordinates the Alaska Blind Child Discovery which has received discounted vision screening technology from several vendors. He is an investigator and protocol developer for the NIH-funded Pediatric Eye Disease Investigator Group. No other co-author has financial conflicts. The authors report no other conflicts of interest for this work.

\section{References}

1. Dunville LM, Sood G, Kramer J. Oculocardiac reflex. StatPearls Website; Published 2020. Available from: https://www.ncbi.nlm.nih. gov/pubmed/29763007. Accessed October 18, 2020.

2. Schaller B, Cornelius JF, Prabhakar H, et al. The trigemino-cardiac reflex: an update of the current knowledge. J Neurosurg Anesthesiol. 2009;21(3):187-195. doi:10.1097/ANA.0b013e3181a2bf22 
3. Scheiermann P, Herzog F, Siebenhofer A, Strametz R, Weberschock T. Intravenous versus inhalational anesthesia for pediatric inpatient surgery - a systematic review and meta-analysis. J Clin Anesth. 2018;49: 19-25. doi:10.1016/j.jclinane.2018.05.014

4. Arnold RW, Farah RS, Monroe G. The attenuating effect of intraglossal atropine on the oculocardiac reflex. Binocul Vis Strabismus $Q$. 2002;17(4):313-318.

5. Arnold RW, Jensen PA, Kovtoun TA, Maurer SA, Schultz JA. The profound augmentation of the oculocardiac reflex by fast acting opioids. Binocul Vis Strabismus Q. 2004;19(4):215-222.

6. Machida CJ, Arnold RW. The effect of induced muscle tension and fatigue on the oculocardiac reflex. Binoc Vis and Strabismus Quart. 2003;18(2):81-86.

7. Chung CJ, Lee JM, Choi SR, Lee SC, Lee JH. Effect of remifentanil on oculocardiac reflex in paediatric strabismus surgery. Acta Anaesthesiol Scand. 2008;52(9):1273-1277. doi:10.1111/j.1399-6576. 2008.01745.x

8. Arnold RW, Biggs RE, Beerle BJ. Intravenous dexmedetomidine augments the oculocardiac reflex. J AAPOS. 2018;22(3):211-213.e211 doi:10.1016/j.jaapos.2018.01.016

9. Ha SG, Huh J, Lee BR, Kim SH. Surgical factors affecting oculocardiac reflex during strabismus surgery. BMC Ophthalmol. 2018;18 (1):103. doi:10.1186/s12886-018-0771-9

10. Khurana I, Sharma R, Khurana AK. Experimental study of oculocardiac reflex (OCR) with graded stimuli. Indian J Physiol Pharmacol. 2006;50(2):152-156.

11. Taylor C, Wilson F, Roesch R, Stoelting V. Prevention of the oculocardiac reflex in children: comparison of retrobulbar block and intravenous atropine. Anesthesiology. 1963;24(5):646-649. doi:10.1097/ 00000542-196309000-00012

12. Mendelblatt F, Kirsch R, Lemberg L. A study comparing methods of preventing the oculocardiac reflex. Am J Ophthalmol. 1962;53 (3):506-512. doi:10.1016/0002-9394(62)94883-3

13. Steib A, Karcenty A, Calache E, Franckhauser J, Dupeyron JP, Speeg-Schatz C. Effects of subtenon anesthesia combined with general anesthesia on perioperative analgesic requirements in pediatric strabismus surgery. Reg Anesth Pain Med. 2005;30(5):478-483. doi:10.1016/j.rapm.2005.04.011

14. Arnold RW. The human heart rate response profiles to five vagal maneuvers. Yale J Biol Med. 1999;72(4):237-244.

15. Arnold RW, Hohberger GG, Gould AB. The oculocardiac reflex in identical twins. Arch Ophthalmol. 1988;106(7):879. doi:10.1001/ archopht.1988.01060140021007

16. Arnold RW, Gould AB, McKenzie R, Dyer JA, Low P. Lack of global vagal propensity in oculocardiac reflex patients. Ophthalmology. 1994;101(8):1347-1352. doi:10.1016/S0161-6420(94)31163-8

17. Moonie G, Rees D, Elton D. The oculocardiac reflex during strabismus surgery. Can Anaesth Soc J. 1964;11(6):621-632. doi:10.1007/ BF03004107
18. Kim HS, Kim SD, Kim CS, Yum MK. Prediction of the oculocardiac reflex from pre-operative linear and nonlinear heart rate dynamics in children. Anaesthesia. 2000;55(9):847-852. doi:10.1046/j.1365-20 44.2000.01158.x

19. Kim WO, Kil HK, Lee JS, Lee JH. Prediction of oculocardiac reflex in strabismus surgery using neural networks. Yonsei Med J. 1999;40 (3):244-247. doi:10.3349/ymj.1999.40.3.244

20. Fry E, Hall-Parker J. Eye hue and the oculocardiac reflex. $\mathrm{Br} J$ Ophthalmol. 1978;62(2):116-117. doi:10.1136/bjo.62.2.116

21. Hunsley J, Bush G, Jones C. A study of glycopyrrolate and atropine in the suppression of the oculocardiac reflex during strabismus surgery in children. Br J Anaesth. 1982;54(4):459-464. doi:10.1093/bja/ 54.4.459

22. Ohashi T, Kase M, Yokoi M. Quantitative analysis of oculocardiac reflex by traction on human extraocular muscle. Invest Ophthalmol Vis Sci. 1986;27:1160-1164.

23. Hertle R, Granet D, Zylan S. The intraoperative oculocardiac reflex as a predictor of postoperative vaso-vagal responses during adjustable suture surgery. J Pediatr Ophthalmol Strabismus. 1993;30:306-311.

24. Apt L, Isenberg S. The oculocardiac reflex as a surgical aid in identifying a slipped or 'lost' extraocular muscle. Br J Ophthalmol. 1980;64(5):362-365. doi:10.1136/bjo.64.5.362

25. Stott D. Reflex bradycardia in facial surgery. Br J Plast Surg. 1989;42 (5):595-597. doi:10.1016/0007-1226(89)90053-2

26. Stump M, Arnold RW. Iris color alone does not predict susceptibility to the oculocardiac reflex in strabismus surgery. Binocul Vis Strabismus Q. 1999;14(2):111-116.

27. Arnold RW, Bond AN, McCall M, Lunoe L. The oculocardiac reflex and depth of anesthesia measured by brain wave. BMC Anesthesiol. 2019;19(1):36. doi:10.1186/s12871-019-0712-z

28. Pöntinen PJ. The importance of the oculocardiac reflex during ocular surgery. Acta Ophthalmol (Copenh). 1966;86(suppl):5-66.

29. Apt L, Isenberg S, Gaffney W. The oculocardiac reflex in strabismus surgery. Am J Ophthalmol. 1973;76(4):533-536. doi:10.1016/00029394(73)90743-5

30. Welters ID, Graef M, Menges T, Beikirch C, Kaufmann H, Hempelmann G. Postoperative nausea and vomiting after Faden operation. Graefes Arch Clin Exp Ophthalmol. 2000;238(1):59-63. doi: $10.1007 / \mathrm{s} 004170050010$

31. Welters ID, Menges T, Graf M, Beikirch C, Menzebach A, Hempelmann G. Reduction of postoperative nausea and vomiting by dimenhydrinate suppositories after strabismus surgery in children Anesth Analg. 2000;90(2):311-314. doi:10.1213/00000539-200002 000-00013
Clinical Ophthalmology

\section{Publish your work in this journal}

Clinical Ophthalmology is an international, peer-reviewed journal covering all subspecialties within ophthalmology. Key topics include: Optometry; Visual science; Pharmacology and drug therapy in eye diseases; Basic Sciences; Primary and Secondary eye care; Patient Safety and Quality of Care Improvements. This journal is indexed on PubMed

\section{Dovepress}

Central and CAS, and is the official journal of The Society of Clinical Ophthalmology (SCO). The manuscript management system is completely online and includes a very quick and fair peer-review system, which is all easy to use. Visit http://www.dovepress.com/ testimonials.php to read real quotes from published authors. 